\title{
Gas Phase Protolysis of Trisarylzincate Anions
}

\author{
Rene Rahrt and Konrad Koszinowski* \\ Institut für Organische und Biomolekulare Chemie, Universität Göttingen, Tammannstraße 2, \\ 37077 Göttingen, Germany
}

\section{Supporting Information}

\section{Table of contents}

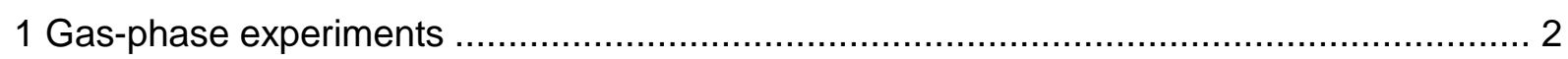

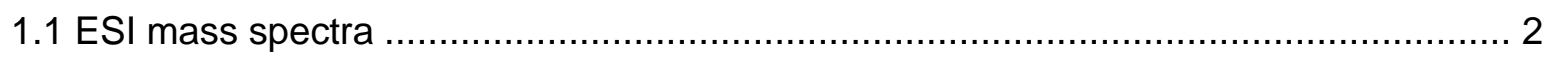

1.2 Kinetic measurements of the trisarylzincate anion protolysis .................................. 5

1.3 Hammett analysis for experimental rate constants............................................ 8

2 Quantum-chemical computations ...................................................................... 9

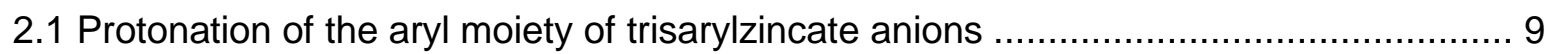

2.2 Protonation of the phenyl moiety of trisarylzincate anions ......................................

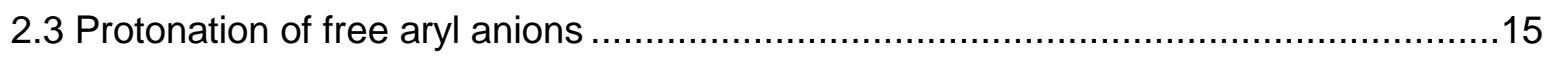

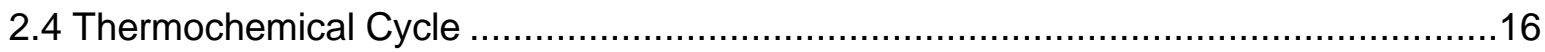

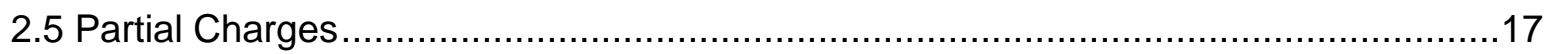

\section{Data availability}

Replication data will be available in the Göttingen Research Online repository GRO.data (Koszinowski Group Dataverse > Rahrt Dataverse > Protonation of Organometallics Dataverse): https://data.goettingen-research-online.de/dataverse/rahrt-01

The data set of this publication contains: $X Y$ files of source mass spectra, $X Y$ files of kinetic measurements, $X Y Z$ coordinates and energies of computed structures as well as exemplary ORCA input files, COLRATE input files and MESMER input files. 


\section{Gas-phase experiments}

\subsection{ESI mass spectra}

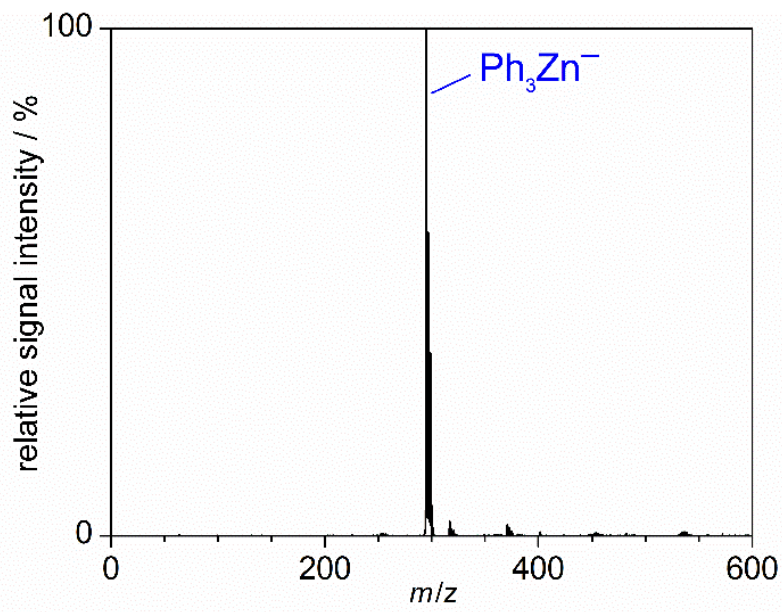

Figure S1: Negative-ion mode ESI mass spectrum of a solution of the products formed upon the reaction of $\mathrm{ZnCl}_{2}$ with $\mathrm{PhLi}$ (4 equiv.) in THF (20 mM) at $0{ }^{\circ} \mathrm{C}$.

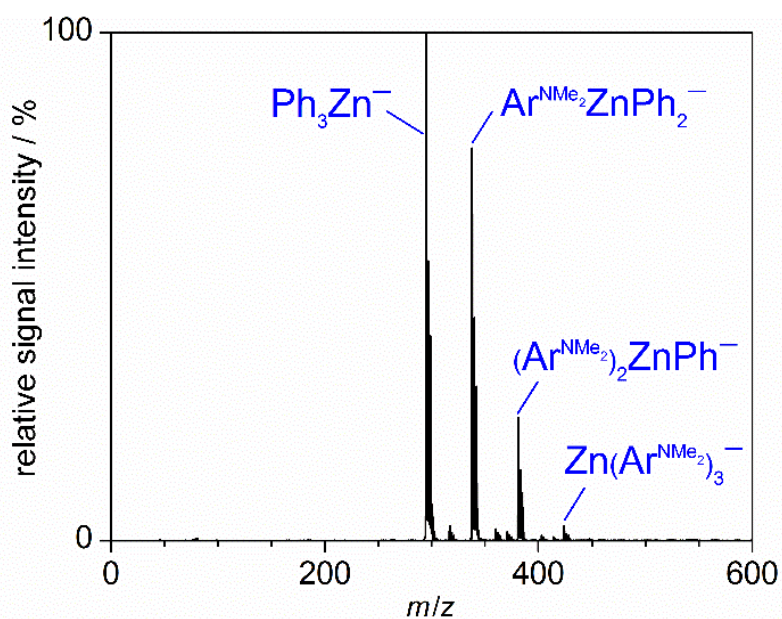

Figure S2: Negative-ion mode ESI mass spectrum of a solution of the products formed upon the reaction of $\mathrm{ZnCl}_{2}$ with $\mathrm{PhLi}$ (2 equiv.) and $\mathrm{Ar}^{\mathrm{NMe}_{2}} \mathrm{MgBr}$ (2 equiv.) in $\mathrm{THF}(20 \mathrm{~mm})$ at $0{ }^{\circ} \mathrm{C}$. 


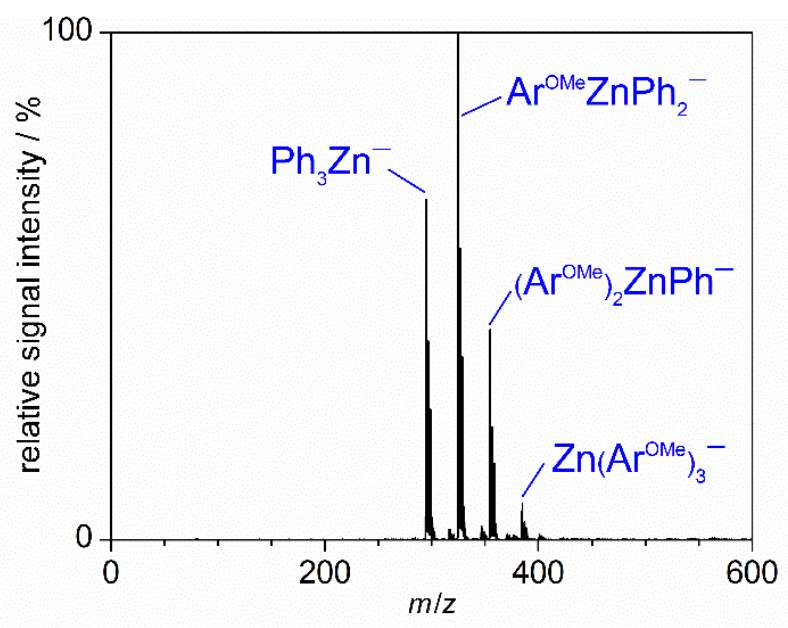

Figure S3: Negative-ion mode ESI mass spectrum of a solution of the products formed upon the reaction of $\mathrm{ZnCl}_{2}$ with $\mathrm{PhLi}$ (2 equiv.) and $\mathrm{Ar}{ }^{\mathrm{OMe}} \mathrm{MgBr}$ (2 equiv.) in $\mathrm{THF}\left(20 \mathrm{mM}\right.$ ) at $0{ }^{\circ} \mathrm{C}$.

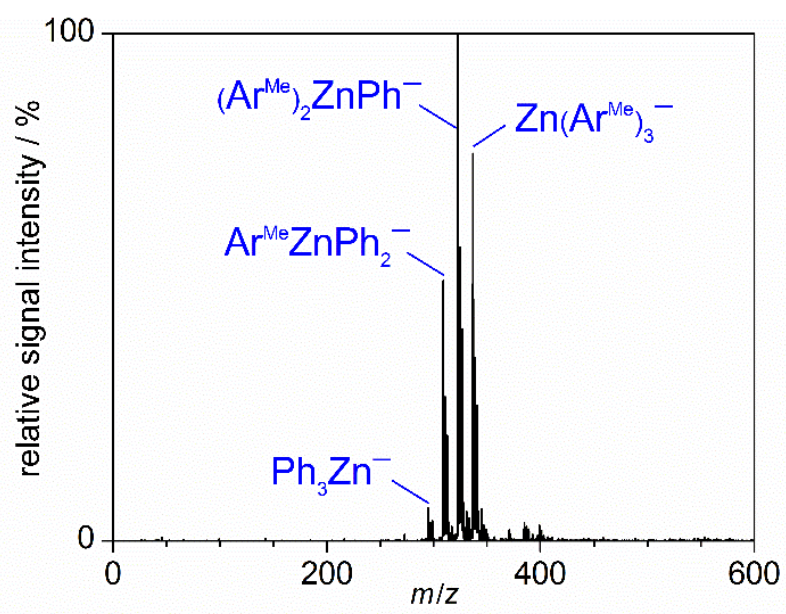

Figure S4: Negative-ion mode ESI mass spectrum of a solution of the products formed upon the reaction of $\mathrm{ZnCl}_{2}$ with $\mathrm{PhLi}$ (2 equiv.) and $\mathrm{Ar}^{\mathrm{Me}} \mathrm{MgBr}$ (2 equiv.) in $\mathrm{THF}\left(20 \mathrm{mM}\right.$ ) at $0{ }^{\circ} \mathrm{C}$. 


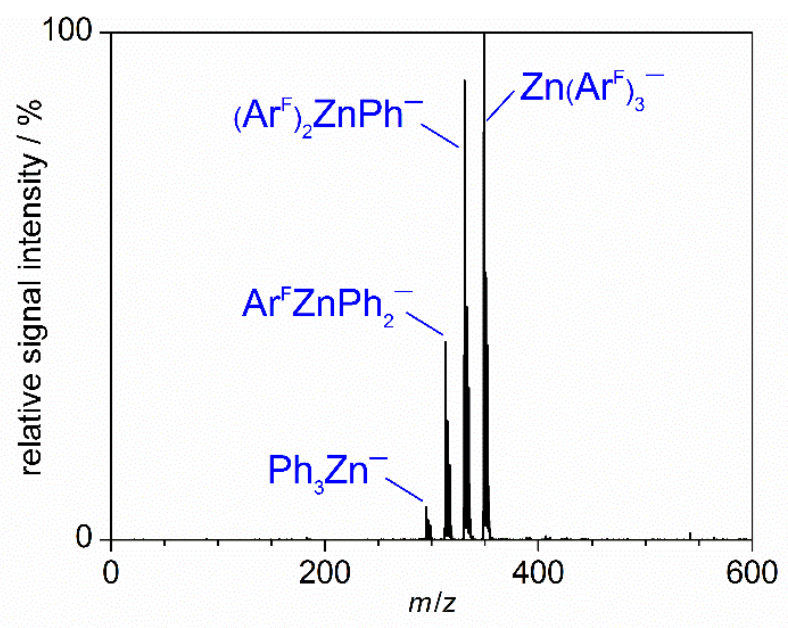

Figure S5: Negative-ion mode ESI mass spectrum of a solution of the products formed upon the reaction of $\mathrm{ZnCl}_{2}$ with $\mathrm{PhLi}$ (3 equiv.) and $\mathrm{Ar}^{\mathrm{F}} \mathrm{MgBr}$ (1 equiv.) in $\mathrm{THF}\left(20 \mathrm{mM}\right.$ ) at $0{ }^{\circ} \mathrm{C}$.

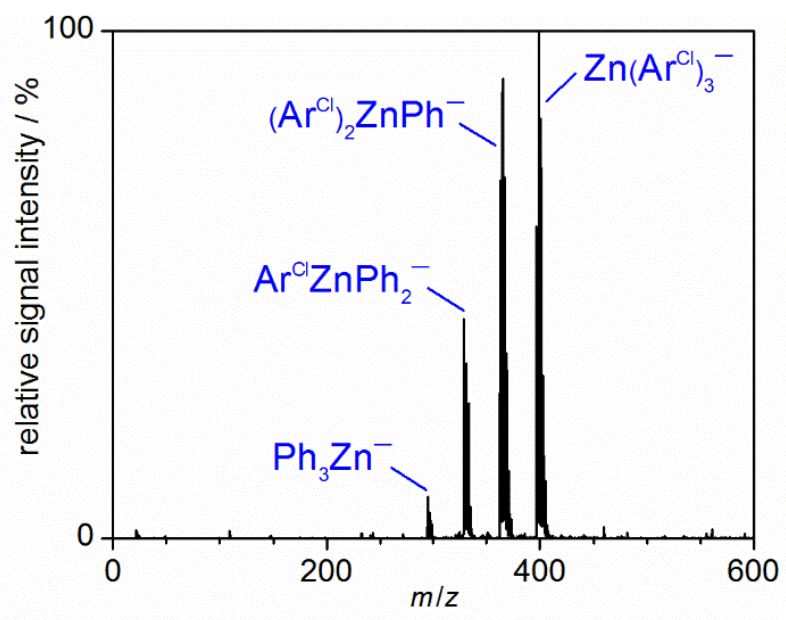

Figure S6: Negative-ion mode ESI mass spectrum of a solution of the products formed upon the reaction of $\mathrm{ZnCl}_{2}$ with $\mathrm{PhLi}$ (3 equiv.) and $\mathrm{Ar}{ }^{\mathrm{Cl}} \mathrm{MgBr}$ (1 equiv.) in $\mathrm{THF}\left(20 \mathrm{mM}\right.$ ) at $0{ }^{\circ} \mathrm{C}$. 
1.2 Kinetic measurements of the trisarylzincate anion protolysis

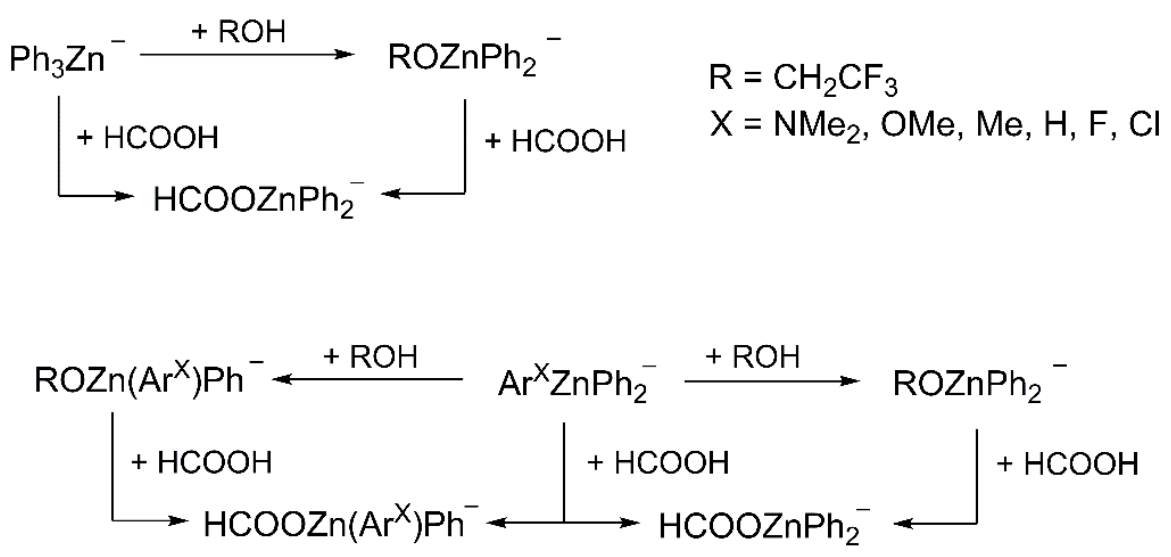

Scheme S1: Reaction networks for the protonation of the triphenylzincate anion (top) and para-substituted trisarylzincate anions (bottom) by 2,2,2-trifluoroethanol (ROH) and traces of contaminant formic acid $(\mathrm{HCOOH})$.

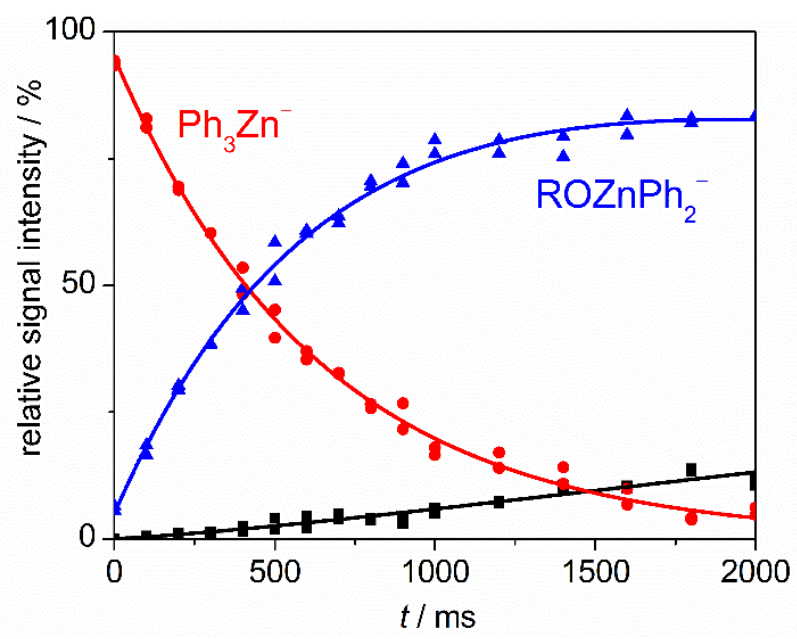

Figure S7: Kinetic profile of the gas-phase reaction of mass-selected $\mathrm{Ph}_{3} \mathrm{Zn}^{-}$with 2,2,2trifluoroethanol yielding $\mathrm{ROZnPh}_{2}^{-}$and benzene. Black: $\mathrm{HCOOZnPh}_{2}{ }^{-}$. The formatecontaining ion results from reactions with residual traces of $\mathrm{HCOOH}$ present in the QIT. 


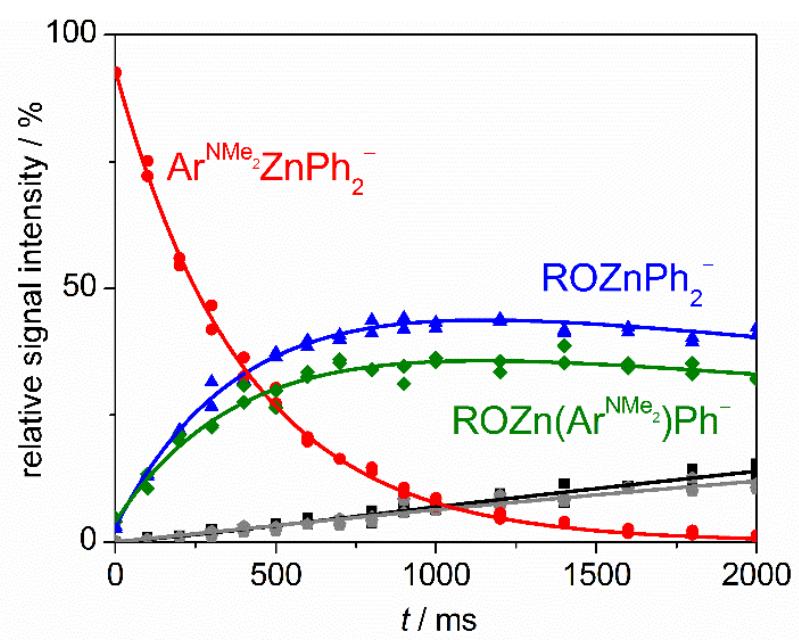

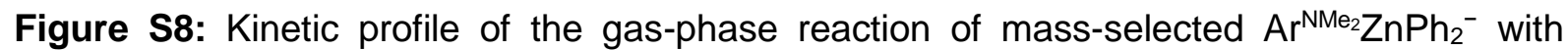
2,2,2-trifluoroethanol yielding $\mathrm{ROZnPh}_{2}{ }^{-}$and $N, N$-dimethylaniline as well as $\mathrm{ROZn}\left(\mathrm{Ar}^{\mathrm{NM} e_{2}}\right) \mathrm{Ph}^{-}$ and benzene. Black: $\mathrm{HCOOZnPh}_{2}{ }^{-}$, gray: $\mathrm{HCOOZn}\left(\mathrm{Ar}^{\mathrm{NMe}_{2}}\right) \mathrm{Ph}^{-}$. The formate-containing ions result from reactions with residual traces of $\mathrm{HCOOH}$ present in the QIT.

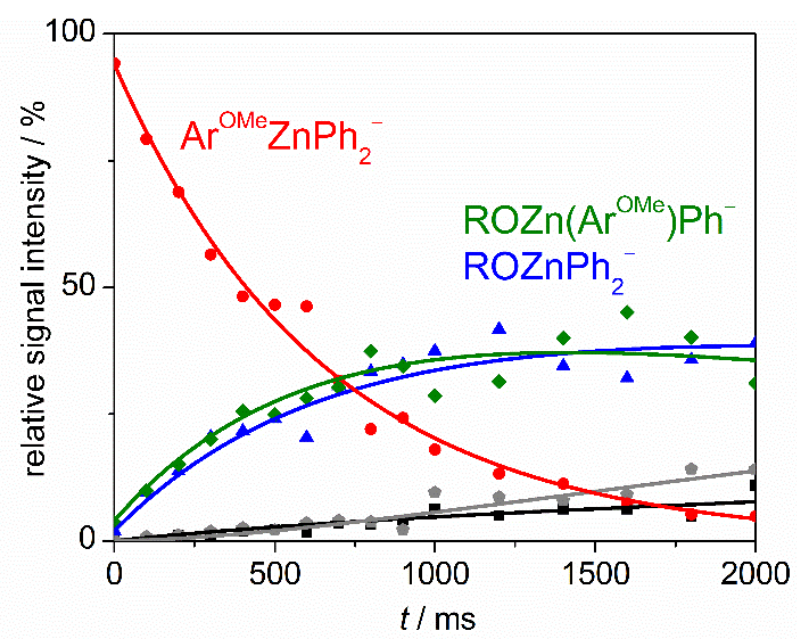

Figure S9: Kinetic profile of the gas-phase reaction of mass-selected $\mathrm{Ar}^{\mathrm{OM}} \mathrm{ZnPh}_{2}{ }^{-}$with 2,2,2trifluoroethanol yielding $\mathrm{ROZnPh}_{2}{ }^{-}$and anisole as well as $\mathrm{ROZn}\left(\mathrm{Ar}^{\mathrm{OMe}}\right) \mathrm{Ph}^{-}$and benzene. Black: $\mathrm{HCOOZnPh}_{2}{ }^{-}$, gray: $\mathrm{HCOOZn}\left(\mathrm{Ar}^{\mathrm{OMe}}\right) \mathrm{Ph}^{-}$. The formate-containing ions result from reactions with residual traces of $\mathrm{HCOOH}$ present in the QIT. 


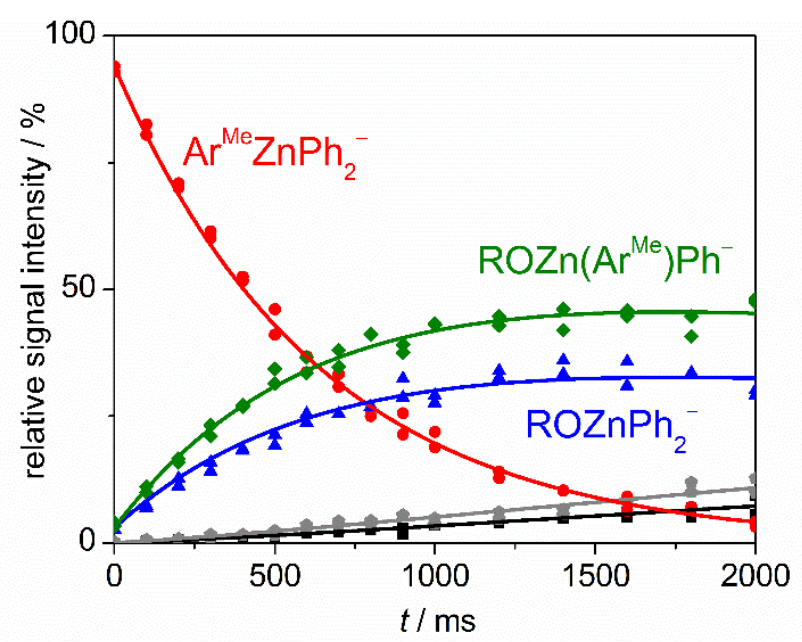

Figure S10: Kinetic profile of the gas-phase reaction of mass-selected $\mathrm{Ar}^{\mathrm{Me}} \mathrm{ZnPh}_{2}{ }^{-}$with 2,2,2-trifluoroethanol yielding $\mathrm{ROZnPh}_{2}{ }^{-}$and toluene as well as $\mathrm{ROZn}\left(\mathrm{Ar}^{\mathrm{Me}}\right) \mathrm{Ph}^{-}$and benzene. Black: $\mathrm{HCOOZnPh}_{2}{ }^{-}$, gray: $\mathrm{HCOOZn}\left(\mathrm{Ar}^{\mathrm{Me}}\right) \mathrm{Ph}^{-}$. The formate-containing ions result from reactions with residual traces of $\mathrm{HCOOH}$ present in the QIT.

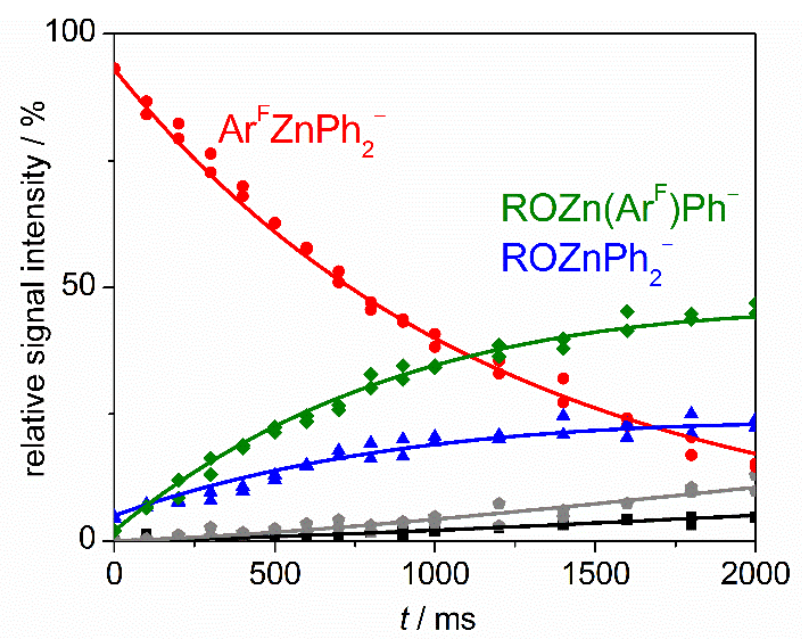

Figure S11: Kinetic profile of the gas-phase reaction of mass-selected $\mathrm{ArFnPh}_{2}{ }^{-}$with 2,2,2trifluoroethanol yielding $\mathrm{ROZnPh}_{2}^{-}$and fluorobenzene as well as $\mathrm{ROZn}\left(\mathrm{Ar}^{\mathrm{F}}\right) \mathrm{Ph}^{-}$and benzene. Black: $\mathrm{HCOOZnPh}_{2}^{-}$, gray: $\mathrm{HCOOZn}\left(\mathrm{Ar}^{\mathrm{F}}\right) \mathrm{Ph}^{-}$. The formate-containing ions result from reactions with residual traces of $\mathrm{HCOOH}$ present in the QIT. 
1.3 Hammett analysis for experimental rate constants

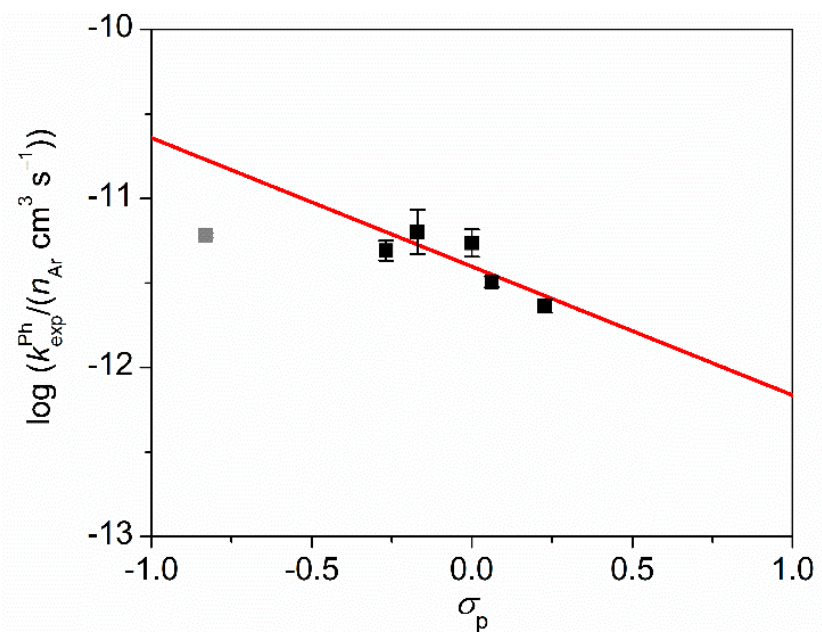

Figure S12: Hammett analysis for the protonation of one phenyl moiety in different parasubstituted trisarylzincates $\mathrm{Ar}^{\times} \mathrm{ZnPh}_{2}^{-}\left(\mathrm{X}=\mathrm{NMe}_{2}, \mathrm{OMe}, \mathrm{Me}, \mathrm{H}, \mathrm{F}, \mathrm{Cl}\right)$ by 2,2,2trifluoroethanol. Excluding the point for $\mathrm{X}=\mathrm{NMe}_{2}$, the data fit a linear regression with a slope of $-0.76\left(R^{2}=0.56\right)$. 


\section{Quantum-chemical computations}

2.1 Protonation of the aryl moiety of trisarylzincate anions

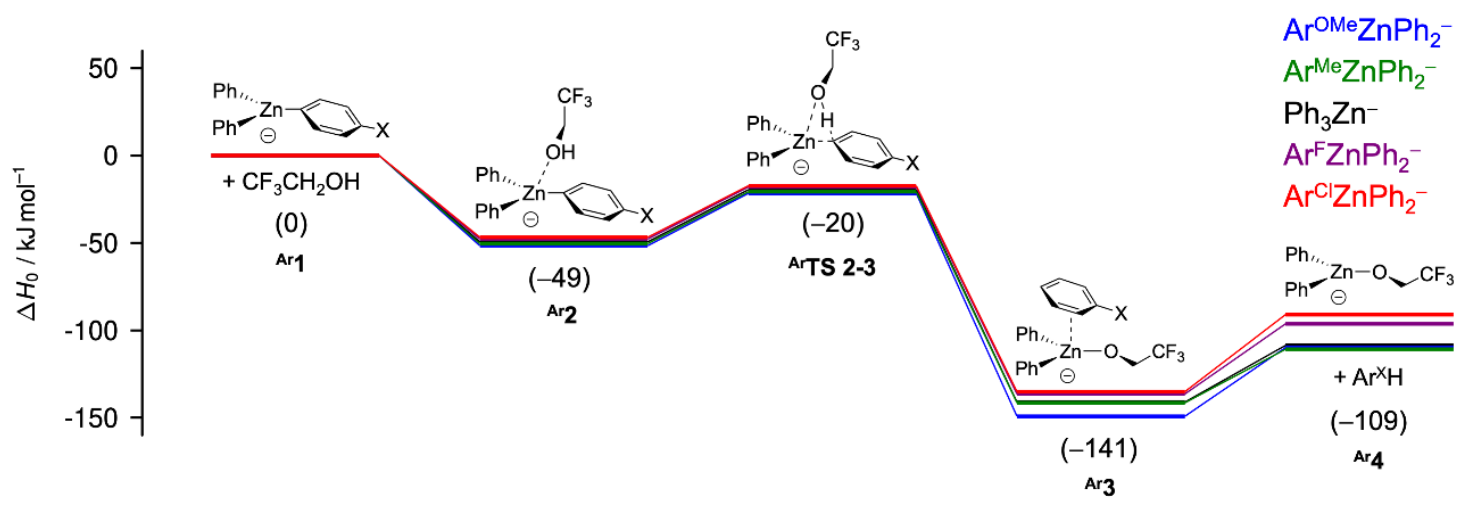

Figure S13: Energy profiles for the protonation of the aryl moiety of different trisarylzincates $\mathrm{Ar}^{\mathrm{X}} \mathrm{ZnPh}_{2}^{-}(\mathrm{X}=\mathrm{OMe}, \mathrm{Me}, \mathrm{H}, \mathrm{F}, \mathrm{Cl})$ by 2,2,2-trifluoroethanol in the gas phase at $0 \mathrm{~K}$. Enthalpies $H_{0}$ were calculated at the DLPNO-CCSD(T)/cc-pV[T;Q]Z//wB97X-D3/def2-TZVP level of theory and are given relative to the reactants. The values given in brackets refer to the unsubstituted triphenylzincate system (black).

Table S1: Calculated energies $\Delta H_{0}$ of the structures ${ }^{\mathrm{Ar}} \mathbf{2}$ to ${ }^{\mathrm{Ar}} \mathbf{4}$ for the protonation of the aryl moiety of different trisarylzincates $\mathrm{Ar}^{\mathrm{X}} \mathrm{ZnPh}_{2}^{-}(\mathrm{X}=\mathrm{OMe}, \mathrm{Me}, \mathrm{H}, \mathrm{F}, \mathrm{Cl})$ by 2,2,2trifluoroethanol in the gas phase at $0 \mathrm{~K}$. Enthalpies $H_{0}$ were calculated at the DLPNO$\operatorname{CCSD}(\mathrm{T}) / \mathrm{cc}-\mathrm{pV}[\mathrm{T} ; \mathrm{Q}] \mathrm{Z} / / \omega \mathrm{B} 97 \mathrm{X}-\mathrm{D} 3 / \mathrm{def} 2-\mathrm{TZVP}$ level of theory, if not noted otherwise, and are given relative to the reactants ${ }^{\mathrm{Ar}}$.

\begin{tabular}{|c|c|c|c|c|}
\hline \multirow[b]{2}{*}{$\mathbf{X}$} & \multicolumn{4}{|c|}{$\Delta H_{0} / \mathrm{kJ} \mathrm{mol}^{-1}$} \\
\hline & Ar2 & ArTS 2-3 & Ar3 & $\operatorname{Ar} 4$ \\
\hline $\mathrm{OMe}$ & -52 & -22 & -149 & -110 \\
\hline $\mathrm{Me}$ & -50 & -21 & -141 & -111 \\
\hline $\mathrm{H}$ & -49 & -20 & -141 & -109 \\
\hline H (wB97X-D3) & -55 & -25 & -148 & -114 \\
\hline H (DSD-PBEP86) & -55 & -31 & -142 & -107 \\
\hline$F$ & -48 & -18 & -136 & -96 \\
\hline $\mathrm{Cl}$ & -47 & -17 & -135 & -91 \\
\hline
\end{tabular}




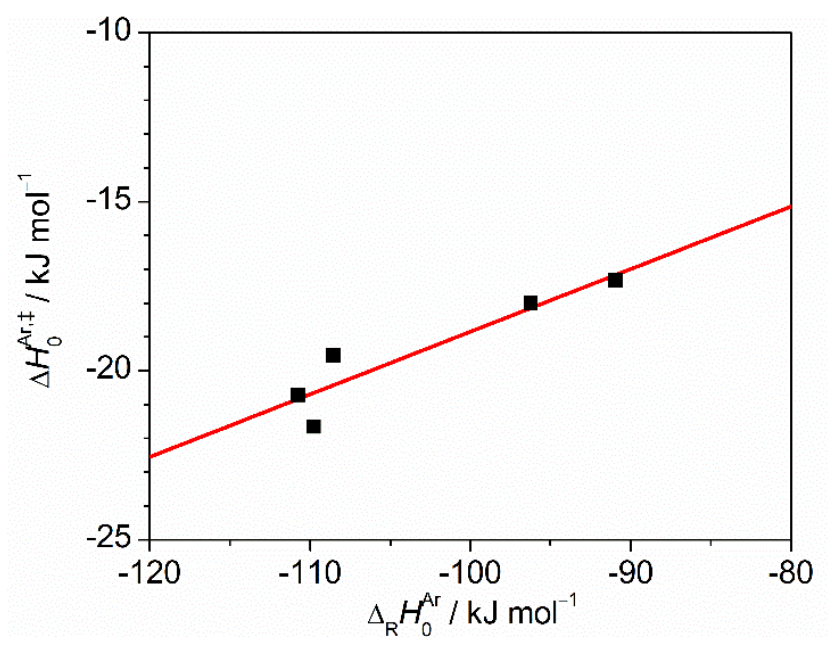

Figure S14: Correlation of computed central barriers $\Delta H_{0}^{\mathrm{Ar}, \neq}$ with the reaction enthalpy $\triangle_{\mathrm{R}} H_{0}{ }^{\mathrm{Ar}}$ for the protonation of the aryl moiety of different para-substituted trisarylzincate $\mathrm{Ar}^{\mathrm{X}} \mathrm{ZnPh}_{2}^{-}(\mathrm{X}=\mathrm{OMe}, \mathrm{Me}, \mathrm{H}, \mathrm{F}, \mathrm{Cl})$ by 2,2,2-trifluoroethanol. Red line: linear fit with a slope of $0.2\left(R^{2}=0.81\right)$.

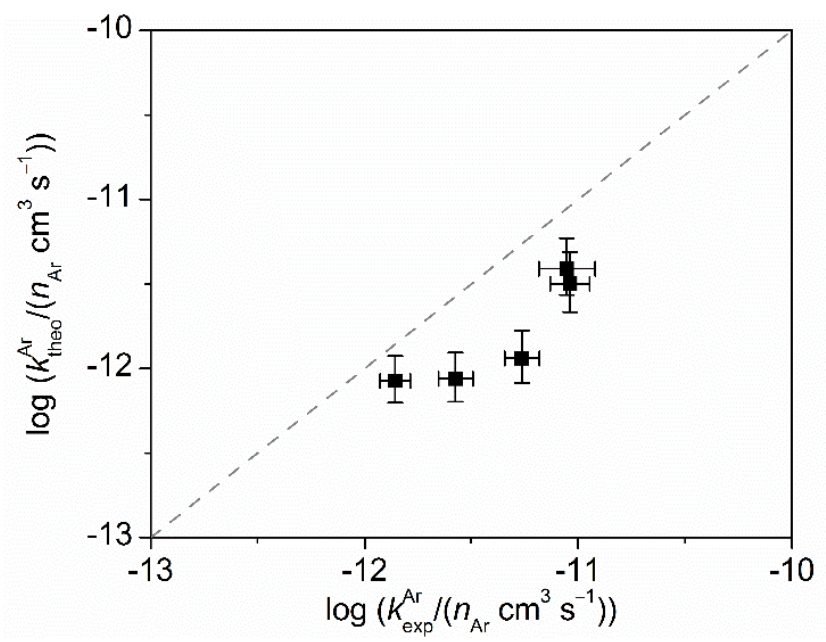

Figure S15: Normalized experimental and theoretical rate constants, $k^{\mathrm{Ar}}$ exp and $k^{\mathrm{Ar}}$ theo, for the protonation of one aryl moiety in para-substituted trisarylzincate anions $\mathrm{Ar}^{\mathrm{X}} \mathrm{ZnPh}_{2}^{-}(\mathrm{X}=\mathrm{OMe}$, $\mathrm{Me}, \mathrm{H}, \mathrm{F}, \mathrm{Cl})$ are correlated with each other. The experimental error corresponds to the double standard deviations of duplicate measurements for each system and the theoretical errors to the uncertainty of the temperature in the ion trap $(310 \mathrm{~K} \pm 20 \mathrm{~K})$. 


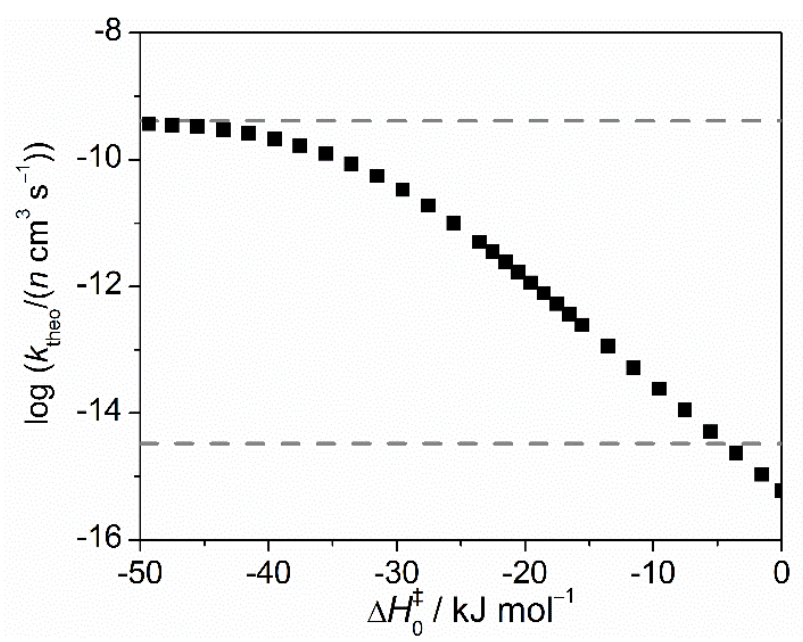

Figure S16: Theoretical rate constant, $k_{\text {theo, }}$, for the protonation of one phenyl moiety in triphenylzincate, $\mathrm{Ph}_{3} \mathrm{Zn}^{-}$, as a function of the central barrier $\Delta H_{0}^{\ddagger}$. The rate constant depends linearly on the barrier height for central barriers higher than $-25 \mathrm{~kJ} \mathrm{~mol}^{-1}$ and, eventually, reaches the limit for the experimental observation by our setup (lower gray dashed line). For $\Delta H_{0}^{\ddagger}<-25 \mathrm{~kJ} \mathrm{~mol}^{-1}$, the rate constant converges towards the collision rate limit (upper gray dashed line), i.e., the capture rate for the formation of the association complex, and thus, the linear correlation no longer holds. 
2.2 Protonation of the phenyl moiety of trisarylzincate anions

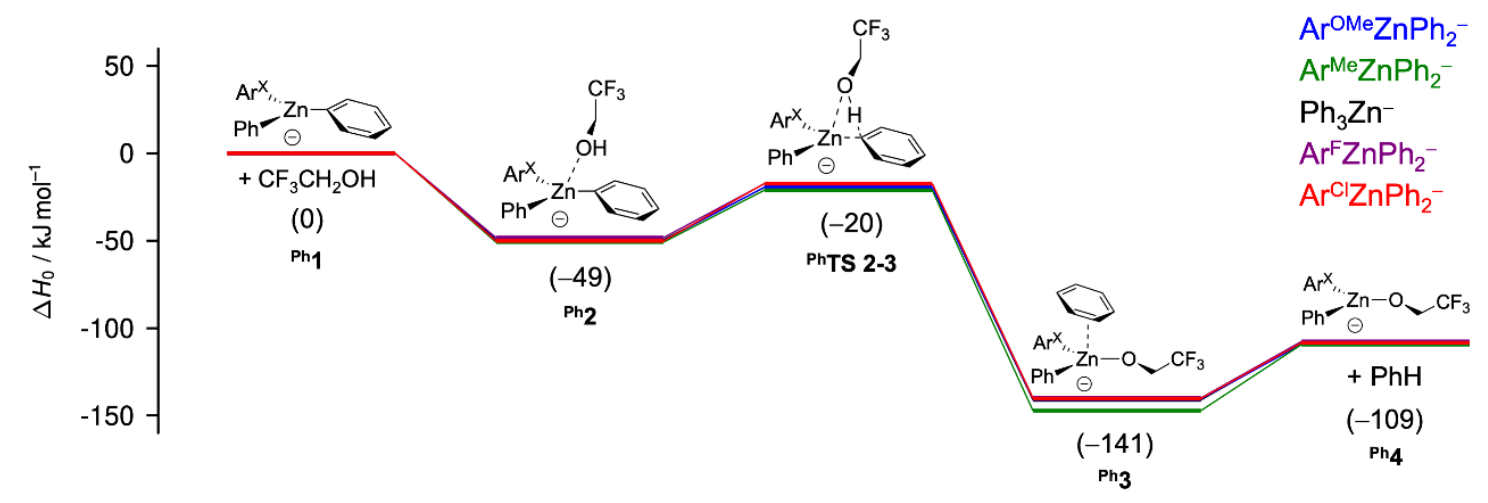

Figure S17: Energy profiles for the protonation of the phenyl moiety of different trisarylzincates $\mathrm{Ar}^{\mathrm{X} Z n \mathrm{Zh}_{2}}{ }^{-}(\mathrm{X}=\mathrm{OMe}, \mathrm{Me}, \mathrm{H}, \mathrm{F}, \mathrm{Cl})$ by 2,2,2-trifluoroethanol in the gas phase at $0 \mathrm{~K}$. Enthalpies $H_{0}$ were calculated at the DLPNO-CCSD(T)/cc-pV[T;Q]Z//wB97X-D3/def2TZVP level of theory and are given relative to the reactants. The values given in brackets refer to the unsubstituted triphenylzincate system (black).

Table S2: Calculated energies $\Delta H_{0}$ of the structures ${ }^{\mathrm{Ph}} \mathbf{2}$ to ${ }^{\mathrm{Ph}} \mathbf{4}$ for the protonation of the phenyl moiety of different trisarylzincates $\mathrm{Ar}^{\mathrm{X}} \mathrm{ZnPh}_{2}^{-}(\mathrm{X}=\mathrm{OMe}, \mathrm{Me}, \mathrm{H}, \mathrm{F}, \mathrm{Cl})$ by 2,2,2trifluoroethanol in the gas phase at $0 \mathrm{~K}$. Enthalpies $H_{0}$ were calculated at the DLPNO$\operatorname{CCSD}(\mathrm{T}) / \mathrm{cc}-\mathrm{pV}[\mathrm{T} ; \mathrm{Q}] \mathrm{Z} / / \omega \mathrm{B} 97 \mathrm{X}-\mathrm{D} 3 / \mathrm{def} 2-\mathrm{TZVP}$ level of theory and are given relative to the reactants ${ }^{\mathrm{Ph}} \mathbf{1}$.

\begin{tabular}{|c|c|c|c|c|}
\hline \multirow[b]{2}{*}{$\mathbf{X}$} & \multicolumn{4}{|c|}{$\Delta H_{0} / \mathrm{kJ} \mathrm{mol}^{-1}$} \\
\hline & $\mathrm{Ph}_{2}$ & ${ }^{\mathrm{Ph}}$ TS 2-3 & $\mathrm{Ph}_{3}$ & $\mathrm{Ph}_{4}$ \\
\hline $\mathrm{OMe}$ & -50 & -19 & -141 & -109 \\
\hline $\mathrm{Me}$ & -51 & -21 & -147 & -109 \\
\hline $\mathrm{H}$ & -49 & -20 & -141 & -109 \\
\hline $\mathrm{F}$ & -48 & -17 & -140 & -108 \\
\hline $\mathrm{Cl}$ & -50 & -17 & -140 & -108 \\
\hline
\end{tabular}

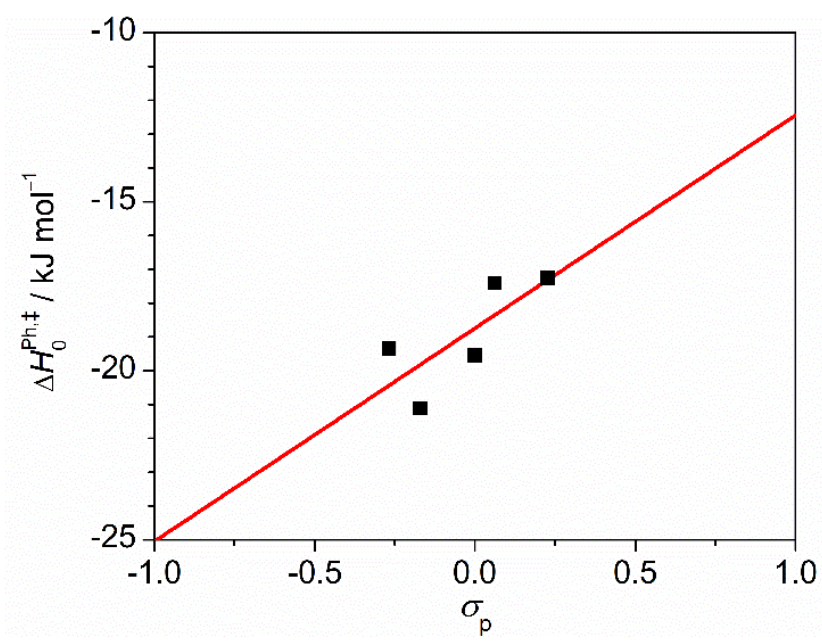

Figure S18: Correlation of the transition state energy $\Delta H_{0}^{\mathrm{Ph}, \ddagger}$ (relative to the reactants) with the Hammett parameter $\sigma_{\mathrm{p}}$ for the protonation of the phenyl moiety in trisarylzincate anions $\mathrm{Ar}^{\mathrm{X}} \mathrm{ZnPh}_{2}{ }^{-}(\mathrm{X}=\mathrm{OMe}, \mathrm{Me}, \mathrm{H}, \mathrm{F}, \mathrm{Cl})$. Red line: linear fit with a slope of $+6.3\left(\mathrm{R}^{2}=0.44\right)$. 


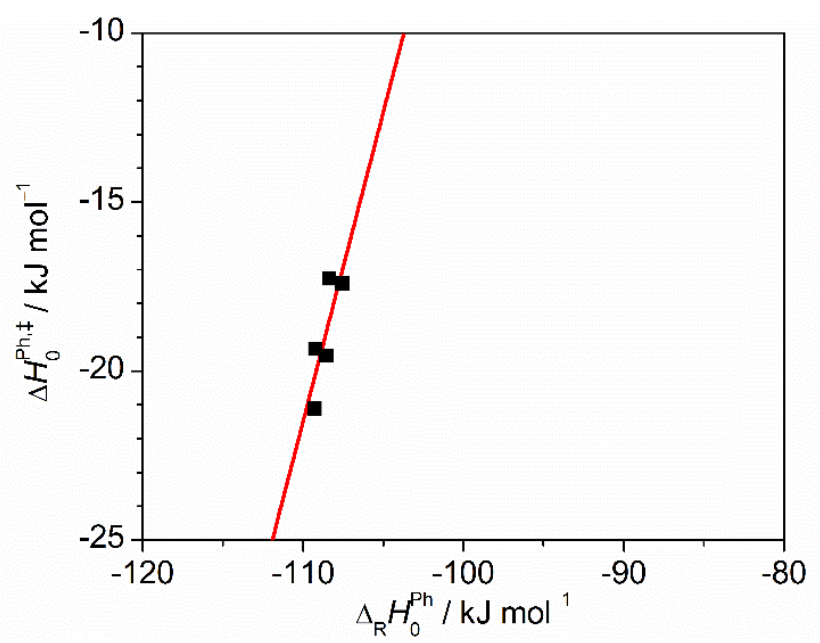

Figure S19: Correlation of computed central barriers $\Delta H_{0}^{\mathrm{Ph}, \ddagger}$ with the reaction enthalpy $\Delta_{\mathrm{R}} H_{0} \mathrm{Ph}$ for the protonation of the phenyl moiety of different para-substituted trisarylzincate $\mathrm{Ar}^{\mathrm{X}} \mathrm{ZnPh}_{2}^{-}(\mathrm{X}=\mathrm{OMe}, \mathrm{Me}, \mathrm{H}, \mathrm{F}, \mathrm{Cl})$ by 2,2,2-trifluoroethanol. Red line: linear fit with a slope of $+1.83\left(R^{2}=0.53\right)$.

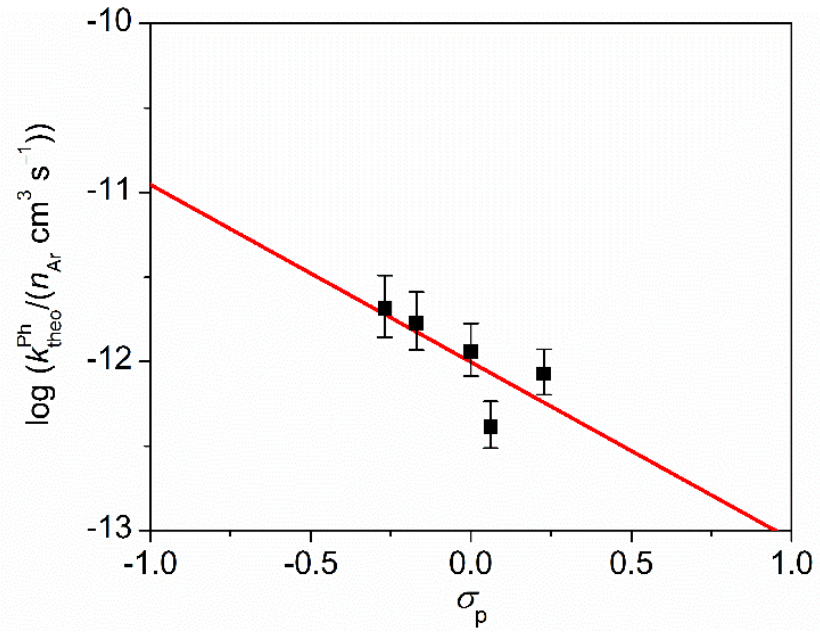

Figure S20: Correlation of the normalized theoretical rate constant $k^{\mathrm{Ph}}{ }_{\text {theo }}$ for the protonation of one phenyl moiety of different para-substituted trisarylzincate $\mathrm{Ar}^{\mathrm{X}} \mathrm{ZnPh}_{2}{ }^{-}(\mathrm{X}=\mathrm{OMe}, \mathrm{Me}, \mathrm{H}$, $\mathrm{F}, \mathrm{Cl}$ ) by 2,2,2-trifluoroethanol with the Hammett parameter $\sigma_{\mathrm{p}}$. The error bars correspond to the doubled uncertainty of the temperature in the ion trap $(310 \mathrm{~K} \pm 20 \mathrm{~K})$. Red line: linear fit with a slope of $-1.1\left(R^{2}=0.40\right)$. 


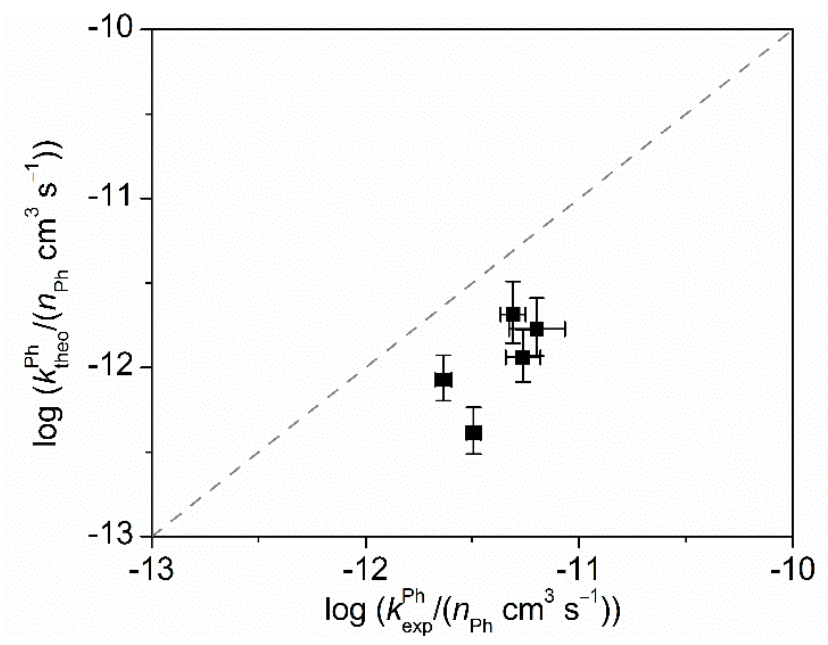

Figure S21: Correlation of the normalized theoretical and experimental rate constants, $k^{\mathrm{Ph}_{\text {theo }}}$ and $k^{\mathrm{Ph}}{ }_{\text {exp }}$, for the protonation of one phenyl moiety in para-substituted trisarylzincate anions $\mathrm{Ar}^{\mathrm{X}} \mathrm{ZnPh}_{2}{ }^{-}(\mathrm{X}=\mathrm{OMe}, \mathrm{Me}, \mathrm{H}, \mathrm{F}, \mathrm{Cl})$. The experimental and theoretical errors correspond to the double standard deviations of duplicate measurements for each system and the uncertainty of the temperature in the ion trap $(310 \mathrm{~K} \pm 20 \mathrm{~K})$, respectively. 
2.3 Protonation of free aryl anions

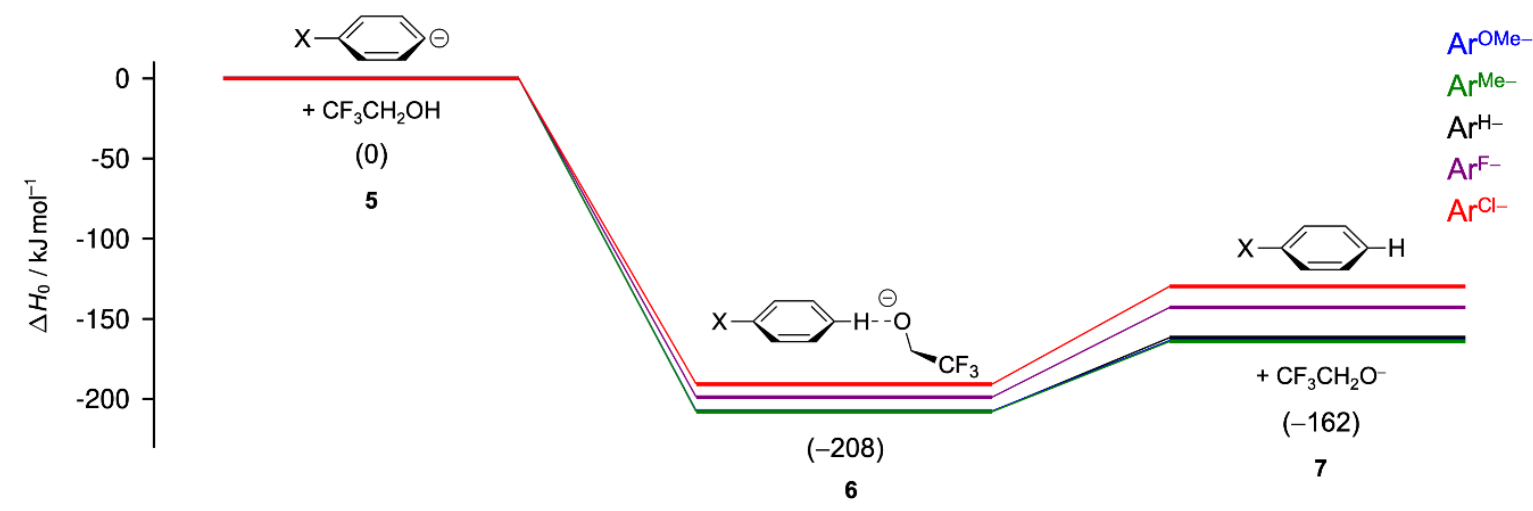

Figure S22: Energy profiles for the protonation of the para-substituted aryl anions $\mathrm{Ar}^{\mathrm{X}-}(\mathrm{X}=$ $\mathrm{OMe}, \mathrm{Me}, \mathrm{H}, \mathrm{F}, \mathrm{Cl}$ ) by 2,2,2-trifluoroethanol in the gas phase at $0 \mathrm{~K}$. Enthalpies $H_{0}$ were calculated at the DLPNO-CCSD(T)/cc-pV[T;Q]Z//wB97X-D3/def2-TZVP level of theory and are given relative to the reactants. The values given in brackets refer to the phenyl system (black).

Table S3: Calculated energies $\Delta H_{0}$ of the structures $\mathbf{6}$ and $\mathbf{7}$ for the protonation of the free aryl anion $\mathrm{Ar}^{\mathrm{X}-}(\mathrm{X}=\mathrm{OMe}, \mathrm{Me}, \mathrm{H}, \mathrm{F}, \mathrm{Cl})$ by 2,2,2-trifluoroethanol in the gas phase at $0 \mathrm{~K}$. Enthalpies $H_{0}$ were calculated at the DLPNO-CCSD(T)/cc-pV[T;Q]Z//wB97X-D3/def2-TZVP level of theory and are given relative to the reactants 5 .

\begin{tabular}{l|ll}
\hline & \multicolumn{2}{|c}{$\Delta \boldsymbol{H}_{\mathbf{0}} / \mathbf{~ k J ~ m o l}^{-\mathbf{1}}$} \\
$\mathbf{X}$ & $\mathbf{6}$ & $\mathbf{7}$ \\
\hline $\mathrm{OMe}$ & -208 & -164 \\
$\mathrm{Me}$ & -208 & -164 \\
$\mathrm{H}$ & -208 & -162 \\
$\mathrm{~F}$ & -199 & -143 \\
$\mathrm{Cl}$ & -191 & -130 \\
\hline
\end{tabular}

Table S4: Collision rates $k_{\text {coll }}$ for the protonation of aryl anions $\mathrm{Ar}^{\mathrm{x}-}$ by 2,2,2-trifluoroethanol as calculated according to the capture rate theory by Su and Chesnavich at $310 \mathrm{~K}$.

\begin{tabular}{l|l}
\hline \multicolumn{1}{c|}{$\mathbf{X}$} & $\boldsymbol{k}_{\text {coll }} / \mathbf{1 0}^{-9} \mathbf{c m}^{3} \mathbf{s}^{-1}$ \\
\hline $\mathrm{OMe}$ & 1.46 \\
$\mathrm{Me}$ & 1.53 \\
$\mathrm{H}$ & 1.60 \\
$\mathrm{~F}$ & 1.51 \\
$\mathrm{Cl}$ & 1.45 \\
\hline
\end{tabular}




\subsection{Thermochemical Cycle}

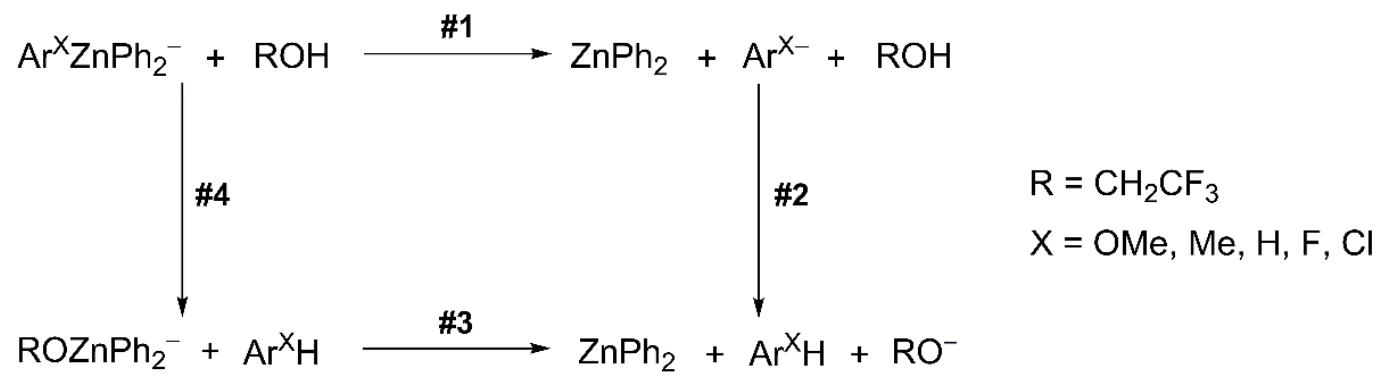

Scheme S2: Thermochemical cycle for the protonation reactions leading from $\mathrm{Ar}^{\mathrm{X}} \mathrm{ZnPh}_{2}{ }^{-}$to diphenylzinc $\mathrm{ZnPh}_{2}$, the arene $\mathrm{Ar}^{\mathrm{X}} \mathrm{H}$, and 2,2,2-trifluoroethoxide $\mathrm{RO}^{-}$.

Table S5: Calculated reaction energies $\Delta_{\mathrm{R}} H_{0}$ for the reactions \#1 to \#4 of the thermochemical cycle according to scheme S2.

\begin{tabular}{|c|c|c|c|c|}
\hline \multirow[b]{2}{*}{$\mathbf{X}$} & \multicolumn{4}{|c|}{$\Delta_{\mathrm{R}} H_{0} / \mathrm{kJ} \mathrm{mol}^{-1}$} \\
\hline & Reaction \#1 & Reaction \#2 & Reaction \#3 & Reaction \#4 \\
\hline $\mathrm{OMe}$ & 280 & -164 & 226 & -110 \\
\hline $\mathrm{Me}$ & 279 & -164 & 226 & -111 \\
\hline $\mathrm{H}$ & 279 & -162 & 226 & -109 \\
\hline $\mathrm{F}$ & 273 & -143 & 226 & -96 \\
\hline $\mathrm{Cl}$ & 265 & -130 & 226 & -91 \\
\hline
\end{tabular}




\subsection{Partial Charges}

Table S6: Calculated partial charges of the carbon acceptor atom in the aryl moiety of parasubstituted trisarylzincate and aryl anions.

\begin{tabular}{|c|c|c|c|}
\hline \multirow[b]{2}{*}{$\mathbf{X}$} & \multicolumn{3}{|c|}{ Partial charge of aryl-carbon acceptor atom } \\
\hline & Mulliken & Loewdin & NPA \\
\hline $\mathrm{Ar}^{\mathrm{OMe}} \mathrm{ZnPh}_{2}^{-}$ & -0.421 & -0.138 & -0.632 \\
\hline $\mathrm{Ar}^{\mathrm{Me}} \mathrm{ZnPh}_{2}^{-}$ & -0.406 & -0.124 & -0.598 \\
\hline $\mathrm{Ph}_{3} \mathrm{Zn}^{-}$ & -0.384 & -0.118 & -0.582 \\
\hline $\mathrm{Ar}^{\mathrm{F} Z n P h}{ }_{2}^{-}$ & -0.398 & -0.129 & -0.612 \\
\hline $\mathrm{Ar}^{\mathrm{Cl}} \mathrm{ZnPh}_{2}^{-}$ & -0.394 & -0.115 & -0.580 \\
\hline ArOMe- & -0.301 & -0.334 & -0.430 \\
\hline $\mathrm{Ar}^{\mathrm{Me}-}$ & -0.247 & -0.319 & -0.397 \\
\hline $\mathrm{Ar}^{\mathrm{H}-}$ & -0.240 & -0.313 & -0.385 \\
\hline $\mathrm{Ar}^{\mathrm{F}-}$ & -0.256 & -0.324 & -0.416 \\
\hline $\mathrm{Ar}^{\mathrm{Cl}}$ & -0.251 & -0.304 & -0.380 \\
\hline
\end{tabular}

